\title{
DISPONIBILIDADE HÍDRICA E O USO DA ÁGUA NA BACIA HIDROGRÁFICA DO RIBEIRÃO PARI/SAMAMBAIA
}

\author{
WATER AVAILABILITY AND USE OF WATER IN THE \\ WATERSHED OF PARI / SAMAMBAIA RIVER
}

\author{
Heber Martins de Paula ${ }^{1}$, Antover Panazzolo Sarmento ${ }^{2}$, \\ Ed Carlo Rosa Paiva ${ }^{3}$, Eliane Aparecida Justino ${ }^{4}$
}

Recebido em 15 de dezembro de 2011; recebido para revisão em 15 de dezembro de 2011; aceito em 27 de dezembro de 2011; disponível on-line em 18 de abril de 2012.

\section{PALAVRAS CHAVES: \\ Ribeirão Pari/Samambaia; \\ Disponibilidade hídrica; \\ Água para abastecimento.}

\section{KEYWORDS:}

Pari/Samambaia River;

Water availability;

Water supply.

\begin{abstract}
RESUMO: Neste trabalho analisou-se a disponibilidade hídrica do manancial superficial na área de abrangência do Ribeirão Pari/Samambaia. Para tal efetuaramse estudos da oferta hídrica da região, com base em dados hidrológicos e climáticos, realizou-se a medição in loco da vazão do Ribeirão Pari/Samambaia, bem como estudos e previsões de uso urbano e agrícola da região. Considerando a vazão mínima determinada e a vazão necessária de água para o abastecimento público, acredita-se que o abastecimento de água para a cidade de Catalão para os próximos anos poderá ser comprometido. Avaliando, ainda, o crescimento urbano da cidade, acima da média nacional, será de suma importância a implantação do gerenciamento e monitoramento da Bacia do Ribeirão Pari/Samambaia.
\end{abstract}

\begin{abstract}
This study analyzed the water surface availability in the catchment area of Ribeirão Pari/Samambaia. Studies of water availability were conducted in the region, based on hydrological and climate data. Measurements were made of the flow of Ribeirão Pari/Samambaia, as well as studies and forecasts for urban and agriculture uses in the region. Considering the minimum flow determined and the required flow of water for public supply, it is believed that the water supply for the city of Catalão for the next years may be compromised. Were evaluated the city's growth, above the national average, will be of paramount importance the implementation of monitoring and management of the Ribeirão Pari/Samambaia.
\end{abstract}

* Contato com os autores:

${ }^{1}$ e-mail : heberdepaula@hotmail.com (H. M. Paula)

Professor do Departamento de Engenharia Civil da Universidade Federal de Goiás, unidade Catalão - GO.

22e-mail : antoverps@hotmail.com (A. P. Sarmento)

Professor do Departamento de Engenharia Civil da Universidade Federal de Goiás, unidade Catalão - GO.

${ }^{3}$ e-mail : edcarlopaiva@yahoo.com.br (E. C. R. Paiva)

Professor do Departamento de Engenharia Civil da Universidade

Federal de Goiás, unidade Catalão - GO.

${ }^{4}$ e-mail : eliane_civ@hotmail.com (E. A. Justino)

Professora do Departamento de Engenharia Civil da Universidade Federal de Goiás, unidade Catalão - GO.

ISSN: 2179-0612 C 2012 REEC - Todos os direitos reservados.

\section{INTRODUÇÃO}

O conhecimento da distribuição espacial dos usos da água é importante no diagnóstico ambiental das bacias hidrográficas, permitindo avaliar como os corpos da água vêm respondendo, em termos quantitativos à intervenção antrópica.

Com o acelerado crescimento populacional e das atividades agrícolas nas últimas décadas no Estado de Goiás, tem-se por consequência o aumento do consumo de água urbana, industrial e agrícola, e uma sensível deterioração da qualidade desse recurso natural.

O Ribeirão Pari/Samambaia tem grande importância para o município de Catalão, pois além de fornecer água 
para o abastecimento urbano e atender às necessidades múltiplas da população é dele que se retira água para a produção de grande parte dos produtos hortifrutigranjeiros da região.

Atualmente o estudo de bacias hidrográficas tem se tornado cada vez mais importante, por essas serem consideradas Unidades de Planejamento Territorial. Para gerir de forma sustentável os recursos naturais do planeta, enfocando os elementos e processos físicobiológicos e socioeconômicos, as bacias hidrográficas apóiam estudos climatológicos destacando a distribuição espacial das chuvas no interior das bacias e, a utilização ordenada dos recursos hídricos para a produção agrícola.

Objetivou-se com este trabalho analisar o potencial hídrico do Ribeirão Pari/Samambaia para o fornecimento de água, para o abastecimento e outros usos no Município de Catalão-GO.

\section{RIBEIRÃO PARI/SAMAMBAIA}

O Ribeirão Pari/Samambaia não consta nos registros da Agência Nacional de Águas (ANA), porém com base em alguns mapas da região que se encontram no Departamento de Geografia da Universidade Federal de Goiás - Campus Catalão pode-se verificar que este é um afluente do Ribeirão Pari que pertence a Unidade Hidrográfica de Referência do Rio Veríssimo situada na sub-bacia do Rio Paranaíba (Figura 1) dentro da Bacia Hidrográfica do Rio Paraná.

Segundo dados obtidos nos mapas georreferenciados da ANA o trecho do Ribeirão Pari que corresponde ao Ribeirão Pari/Samambaia tem 17,03 km de comprimento e conta com uma área de drenagem de $76,81 \mathrm{~km}^{2}$.

O clima no qual se insere o município de Catalão pode ser considerado como tropical-quente-úmido com regime de chuvas sazonal, ocorrendo de outubro a abril. A estação seca é bem definida ocorrendo de março a novembro. Apresentando um índice pluviométrico anual de $1440 \mathrm{~mm}$ e a média da umidade relativa do ar é da ordem de $69 \%$.
$O$ relevo constituinte da bacia pode ser dividido em dois compartimentos topográficos. O primeiro é definido por formas planas a suavemente onduladas e a segunda é definida por uma topografia mais acentuada com declividades mais fortes.

\subsection{Oferta Hídrica da Cidade de Catalão}

A partir das normais climatológicas (período de 1961 a 1990), de temperatura média e precipitação da cidade de Catalão-GO, Sentelhas et al. (2003) utilizando o programa "BHnorm" de Rolim et al. (1998), efetuaram o balanço hídrico da região, podendo este ser visualizado na Tabela 1.

Para uma melhor visualização na Figura 2 podese observar o extrato do Balanço Hídrico Mensal para a região de Catalão-GO.

Como se pode observar na Figura 2, para a Região de Catalão-GO, há um déficit hídrico no período compreendido entre Abril a Outubro, fazendo-se muito importante o monitoramento de vazão principalmente nessa época, por se tratar de um período crítico. Cabe destacar que os regimes pluviométricos influenciam consideravelmente no regime fluviométrico, por isso a oscilação na manutenção do volume a ser captado.

Com os dados de temperatura e precipitação para o período de 2000 a 2009 obtidos da estação climatológica de Catalão (INMET) realizamos um novo balanço hídrico da região para efeito de visualizar a tendência de alteração climática dos últimos 10 anos de dados com a última normal climatológica (1961-1990).

Segue abaixo na Tabela 2 e na Figura 3 o balanço hídrico mensal para a região de Catalão-GO atualizados com os dados de 2000 a 2009.

É notável que nos últimos anos (2000-2009) há uma tendência do prolongamento do período de seca, estendendo-se este até o mês de novembro. 0 monitoramento e o acompanhamento das vazões, ao longo dos anos, do Ribeirão Pari/Samambaia são de suma importância para o planejamento de alternativas de abastecimento, e principalmente se continuar havendo o prolongamento do período de secas.

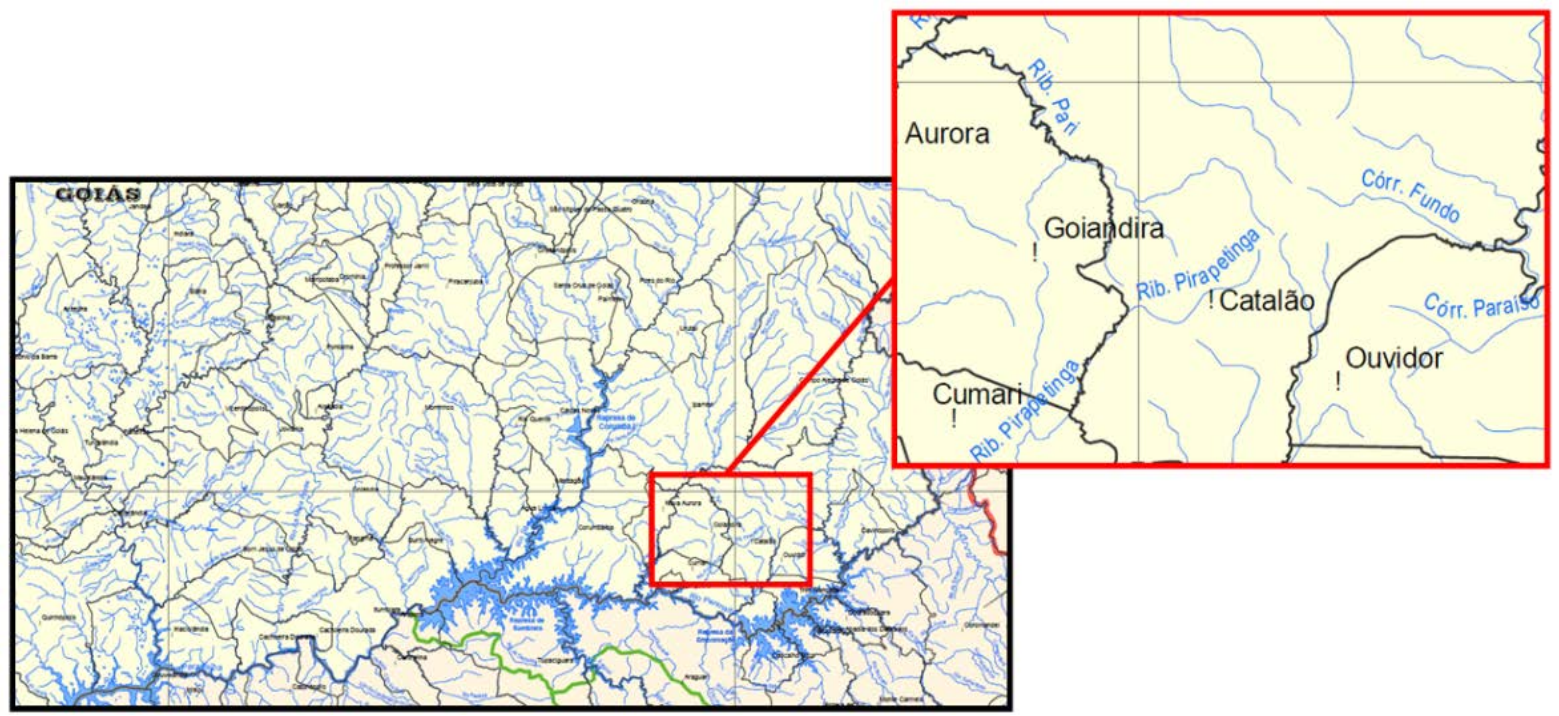

Figura 1: Bacia do Rio Paranaíba com destaque no município de Catalão. Fonte: CBH (2010). 
Tabela 1: Balanço Hídrico Normal (1961-1990) da Região de Catalão-GO.

\begin{tabular}{cccccccc} 
Meses & $\mathbf{T}\left({ }^{\circ} \mathbf{C}\right)$ & $\mathbf{P}(\mathbf{m m})$ & ETP $(\mathbf{m m})$ & ETR $(\mathbf{m m})$ & ARM $(\mathbf{m m})$ & DEF $(\mathbf{m m})$ & EXC (mm) \\
\hline Jan & 23,0 & 272,0 & 104,0 & 104,0 & 100,0 & 0,0 & 168,0 \\
Fev & 23,0 & 217,0 & 95,1 & 95,1 & 100,0 & 0,0 & 121,9 \\
Mar & 23,2 & 172,0 & 104,1 & 104,1 & 100,0 & 0,0 & 67,9 \\
Abr & 22,4 & 80,0 & 88,2 & 87,8 & 92,2 & 0,3 & 0,0 \\
Mai & 20,6 & 31,0 & 70,7 & 61,2 & 62,0 & 9,5 & 0,0 \\
Jun & 19,4 & 10,0 & 56,9 & 33,2 & 38,8 & 23,7 & 0,0 \\
Jul & 19,3 & 10,0 & 57,7 & 24,7 & 24,0 & 33,0 & 0,0 \\
Ago & 21,2 & 14,0 & 74,8 & 25,0 & 13,1 & 49,9 & 0,0 \\
Set & 22,9 & 41,0 & 91,6 & 46,2 & 7,9 & 45,4 & 0,0 \\
Out & 23,3 & 151,0 & 103,4 & 103,4 & 55,5 & 0,0 & 0,0 \\
Nov & 23,0 & 212,0 & 100,9 & 100,9 & 100,0 & 0,0 & 66,6 \\
Dez & 22,6 & 283,0 & 102,4 & 102,4 & 100,0 & 0,0 & 180,6 \\
\hline TOTAIS & 263,9 & 1493,0 & 1049,9 & 888,0 & 793,4 & 161,9 & 605,0 \\
\hline MÉDIAS & 22,0 & 124,4 & 87,5 & 74,0 & 66,1 & 13,5 & 50,4 \\
\hline
\end{tabular}

Fonte: Sentelhas et al.(2003).

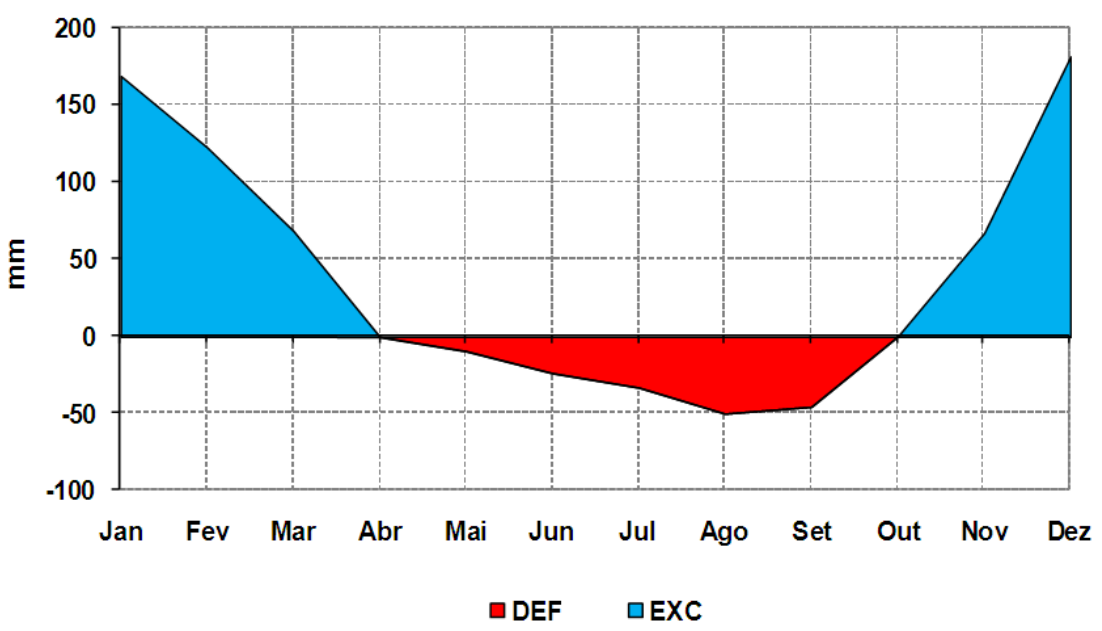

Figura 2: Extrato do Balanço Hídrico Normal Mensal de Catalão-GO. Fonte: Sentelhas et al.(2003).

Tabela 2: Balanço Hídrico Mensal (dados de 2000-2009) da Região de Catalão-GO.

\begin{tabular}{cccccccc} 
Meses & $\mathbf{T}\left({ }^{\mathbf{0}} \mathbf{C}\right)$ & $\mathbf{P}(\mathbf{m m})$ & ETP $(\mathbf{m m})$ & ETR $(\mathbf{m m})$ & ARM $(\mathbf{m m})$ & DEF $(\mathbf{m m})$ & EXC $(\mathbf{m m})$ \\
\hline Jan & 23,5 & 315,3 & 109,53 & 109,5 & 100,00 & 0,0 & 205,8 \\
Fev & 23,6 & 239,5 & 97,70 & 97,7 & 100,00 & 0,0 & 141,8 \\
Mar & 24,1 & 209,6 & 111,30 & 111,3 & 100,00 & 0,0 & 98,3 \\
Abr & 23,5 & 86,8 & 95,38 & 95,0 & 91,77 & 0,4 & 0,0 \\
Mai & 22,1 & 22,4 & 79,60 & 62,3 & 51,77 & 17,2 & 0,0 \\
Jun & 21,3 & 6,3 & 67,04 & 29,8 & 28,19 & 37,2 & 0,0 \\
Jul & 21,5 & 5,4 & 71,02 & 19,0 & 14,63 & 52,0 & 0,0 \\
Ago & 23,2 & 10,0 & 90,44 & 18,0 & 6,54 & 72,4 & 0,0 \\
Set & 24,6 & 44,9 & 107,84 & 47,9 & 3,49 & 59,9 & 0,0 \\
Out & 25,4 & 90,6 & 127,21 & 91,7 & 2,42 & 35,5 & 0,0 \\
Nov & 24,7 & 159,5 & 117,82 & 117,8 & 44,13 & 0,0 & 0,0 \\
Dez & 24,3 & 251,0 & 119,18 & 119,2 & 100,00 & 0,0 & 76,0 \\
\hline TOTAIS & 281,9 & 1441,3 & 1194,06 & 919,4 & 643,0 & 274,7 & 521,9 \\
\hline MÉDIAS & 23,5 & 120,1 & 99,50 & 76,6 & 53,6 & 22,9 & 43,5 \\
\hline
\end{tabular}




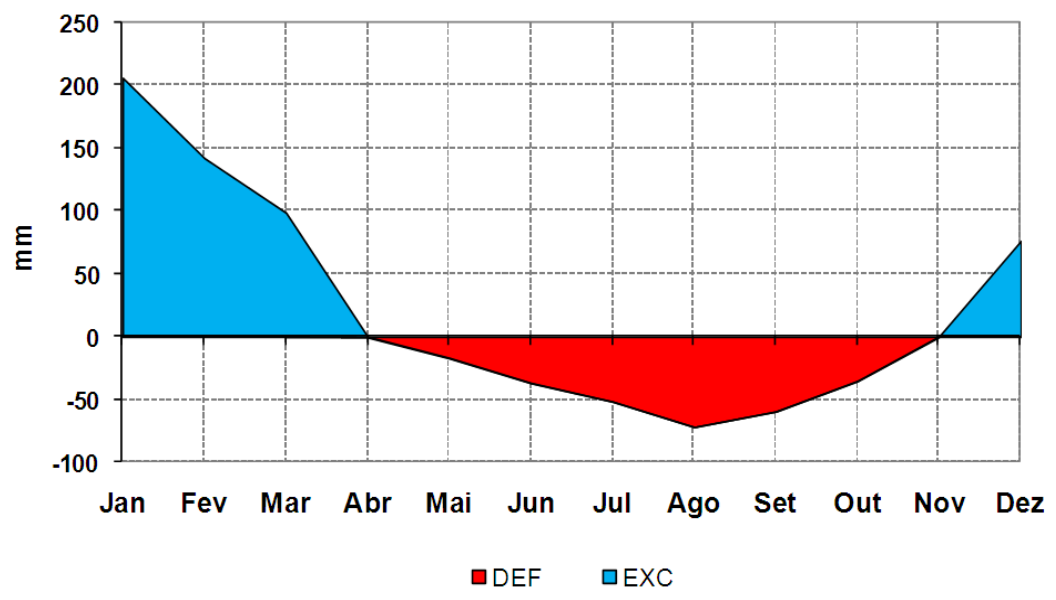

Figura 3: Extrato do Balanço Hídrico Mensal (dados de 2000-2009) de Catalão-GO.

\subsubsection{Monitoramento de Vazão}

É de extrema importância o estudo em relação ao desempenho hídrico da região, em virtude de identificar os meses de maior e menor vazão e suas variações visando um possível racionamento na distribuição de água nos meses de índices críticos.

As medições de vazão foram realizadas nos dias 06 de julho e 11 de agosto do ano de 2011, em um ponto a montante do sistema de captação de água da Superintendência Municipal de Água e Esgotos (SAE) de Catalão, GO. O sistema de captação de água da SAE está localizado sob a longitude de $47^{\circ} 58^{\prime} 40,044^{\prime \prime} \mathrm{O}$ e a latitude de $18^{\circ} 05^{\prime} 14,640$ "S.

Estabeleceu-se uma seção transversal de referência e levantou-se por batimetria a área da seção transversal. Para determinação da vazão, usou-se o método do molinete hidrométrico (Flow Probe Modelo FP 201 da Global Water). Utilizando-se a função AVGspeed foi possível registrar a velocidade média de escoamento em cada ponto de medição.

Desta forma foram registradas as velocidades médias em diversos pontos da seção de referência (a cada 0,50 m), com estes dados de velocidade pôde-se estimar a velocidade média da seção através da técnica de interpolação (Figura 4).

Definida a área da seção transversal e a velocidade média de escoamento na seção, a vazão foi calculada pela equação da continuidade, os resultados podem ser visualizados na Tabela 3 e 4 .

Julho

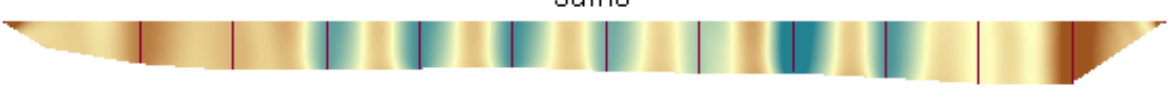

Agosto

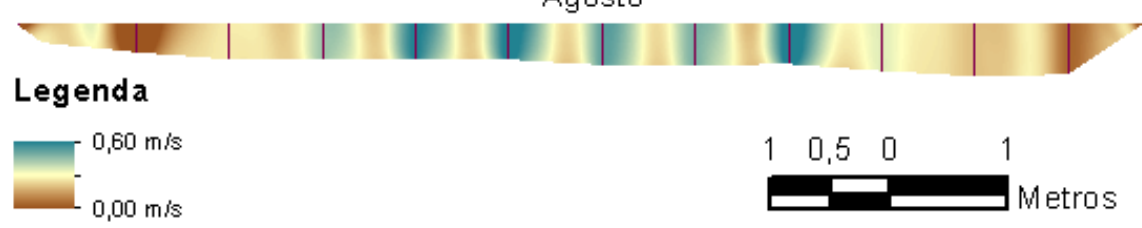

Figura 4: Perfil de velocidade da seção de referência do Ribeirão Pari/Samambaia.

Tabela 3: Características da seção de referência do Ribeirão Pari/Samambaia para o mês de julho de 2011.

\begin{tabular}{lcc} 
Característica & Unidade & Valor \\
\hline Velocidade média & $\mathrm{m} \mathrm{s}^{-1}$ & 0,37 \\
Área & $\mathrm{m}^{2}$ & 1,55 \\
Vazão & $\mathrm{m}^{3} \mathrm{~s}^{-1}$ & 0,58 \\
\hline
\end{tabular}

Tabela 4: Características da seção de referência do Ribeirão Pari/Samambaia para o mês de agosto de 2011.

\begin{tabular}{lcc} 
Característica & Unidade & Valor \\
\hline Velocidade média & $\mathrm{m} \mathrm{s}^{-1}$ & 0,38 \\
Área & $\mathrm{m}^{2}$ & 1,20 \\
Vazão & $\mathrm{m}^{3} \mathrm{~s}^{-1}$ & 0,46 \\
\hline
\end{tabular}


Verifica-se que devido ao período de seca a vazão do Ribeirão Pari/Samambaia apresentou uma redução no mês de agosto frente ao mês de julho de $20,7 \%$. Cabe destacar que será de suma importância o estudo de vazões mínimas ao longo, de pelo menos, um ano para se estabelecer a menor vazão de referência.

Segundo a Resolução no 9 de 2005, que regulamenta a outorga das águas de domínio do Estado de Goiás, a vazão adotada como referência para a outorga do direito de uso das águas de domínio do Estado de Goiás é a vazão com garantia de permanência em $95 \%$ do tempo $\left(Q_{95}\right)$, considerando a bacia de contribuição no ponto de captação, onde esta informação estiver disponível. A soma das vazões outorgadas na bacia, limitada pela seção transversal em estudo, não poderá exceder a $50 \%$ (cinquenta) da vazão de referência.

Nos casos que não existirem as informações hidrológicas necessárias ao cálculo da vazão de referência adotada, como é o presente caso, deverá ser utilizada como vazão de referência a menor vazão medida no local, realizada preferencialmente no período de estiagem e com equipamentos de precisão, sendo que para a vazão medida fora do período de estiagem adotar-se-á um coeficiente de redução com base em séries históricas fluviométricas da bacia hidrográfica.

Considerando as vazões que foram medidas neste trabalho, a menor vazão encontrada foi em agosto (460 L s${ }^{-1}$ ), sendo assim e com base nestes dados considera-se que a vazão que poderia ser outorgada neste trecho do Ribeirão Pari/Samambaia seria de $230 \mathrm{~L} \mathrm{~s}^{-1}$ para a captação e abastecimento da cidade. Isso se não houverem outros usos a jusantes para serem outorgados.

De suma importância ressalta-se a continuidade de monitoramento das vazões no período de estiagem, pois se sabe que este ainda não findou, podendo reduzir ainda mais esta vazão.

\subsubsection{Sistema de Adução Pari/Samambaia}

O sistema de adução Pari/Samambaia é composto por duas estações elevatórias em série: Elevatória de Água Bruta (EAB) Captação Pari/Samambaia e a EAB Intermediária Pari/Samambaia. A elevatória Captação Pari/Samambaia aduz água bruta, da captação no ribeirão, até a Elevatória Intermediária Pari/Samambaia, e essa até a Estação de Tratamento de Água (ETA).

A vazão captada do Ribeirão Pari/Samambaia atualmente é de aproximadamente $195 \mathrm{~L} \mathrm{~s}^{-1}$, o sistema de sucção/recalque do Ribeirão Pari/Samambaia que é feito através de bombeamento funciona 20 horas por dia e mantém uma oferta diária de entorno dos $14040 \mathrm{~m}^{3}$.

\subsection{Demanda de Usos da Água}

\subsubsection{Usos Urbanos}

Segundo o Instituto Brasileiro de Estatística (IBGE, 2009) o município de Catalão apresentou um grande crescimento demográfico como demonstra a Figura 5, em pouco mais de quinze anos a população da cidade ganhou mais de 20 mil habitantes.

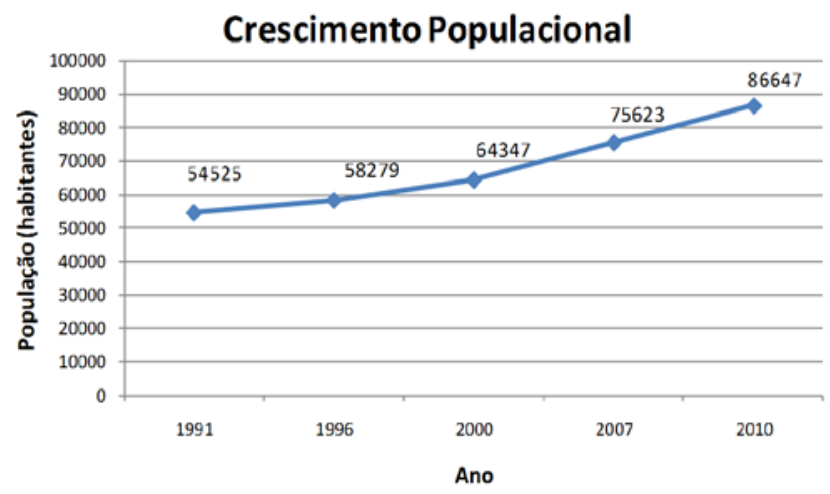

Figura 5. Evolução da população de Catalão do ano de 1991 a 2010.

Fonte: IBGE (2010).

O crescimento populacional influencia diretamente na demanda de recursos hídricos da região, pois com o crescimento está diretamente relacionado a um maior consumo de água, além do aumento do desperdício.

A demanda para o abastecimento urbano é estimada em $150 \mathrm{~L} \mathrm{hab}^{-1} \mathrm{dia}^{-1}$ o que corresponde a um consumo, para o ano de 2010 , de $13000 \mathrm{~m}^{3} \mathrm{dia}^{-1}$ de água, retirada da bacia do Ribeirão Pari/Samambaia.

A captação de água do Ribeirão Pari/Samambaia é de aproximadamente $\quad 702 \mathrm{~m}^{3} \mathrm{~h}^{-1}$, com um índice de abastecimento próximo aos $100 \%$, conforme afirma Fernando Vaz de Ulhôa, superintendente da SAE. Há no município cerca de 30000 ligações com hidrômetros de água tratada divididas entre os setores residencial, industrial e órgãos públicos. Parte da cidade é alimentada por poços artesianos com vazão de aproximadamente 50 $\mathrm{Ls}^{-1}$, e seu funcionamento é de 16 a 18 horas por dia.

A vazão que alimenta os bairros Castelo Branco, Castelinho e Setor Bela Vista, é complementada através da captação de água subterrânea em três poços profundos, localizados no próprio Bairro Castelo Branco.

No bairro Santo Antônio funcionam três poços artesianos. Um quarto poço, localizado no loteamento Alto da Boa Vista, está sendo posto em funcionamento. Esses poços complementam a vazão de abastecimento do reservatório da antiga rodoviária.

$\mathrm{Na}$ área localizada ao lado do Setor Ipanema foram perfurados mais quatro poços que serão colocados em funcionamento e complementarão a vazão produzida pela Estação de Tratamento de Água.

$\mathrm{O}$ consumo de água industrial é bastante intenso, e a partir do desenvolvimento da cidade com a vinda das mineradoras e empresas multinacionais a demanda hídrica de Catalão sofreu um grande impacto, tendo a necessidade de aumentar a oferta. Pode-se citar como exemplo da maior procura de água tratada nos últimos 
anos. A mineradora Fosfértil que, segundo dados fornecidos pelo Sindicado da Indústria de Catalão, possui uma demanda de 333 a $361 \mathrm{~L} \mathrm{~s}^{-1}$ de água. Como o gasto de água da empresa é maior que a captação de água do Ribeirão Pari/Samambaia pela $\mathrm{SAE}$, para atender sua necessidade, a mineradora conta com captação de água superficial ou de poço artesiano.

Avaliando o crescimento da cidade de Catalão para 2020, chegará a uma população de aproximadamente 98175 habitantes, estimando um consumo de água diário de $14700 \mathrm{~m}^{3} \mathrm{dia}^{-1}$, para atender essa demanda a vazão coletada pelo sistema de abastecimento da cidade deverá ser por volta de $240 \mathrm{~L} \mathrm{~s}^{-1}$. Confrontando com os resultados apresentados no item 2.1.1, o Ribeirão Pari/Samambaia poderá não ser capaz de atender a demanda urbana da cidade de Catalão.

Por fim vindo ao encontro deste estudo o relatório de Conjuntura dos Recursos Hídricos no Brasil: informes 2011, elaborado pela ANA, destaca o atlas de abastecimento urbano de água, avaliando a oferta/demanda, faz uma previsão para região de Catalão, apontando a necessidade da adoção de um novo manancial para abastecimento até 2015.

Vale destacar que para a região de Catalão o estudo aponta necessidade de adoção de um novo manancial de abastecimento, como ilustra a Figura 6. Os resultados do Atlas Brasil revelam que 55\% dos municípios necessitam de investimentos para a garantia da oferta de água para o abastecimento urbano, no horizonte de 2015, estimados em $\mathrm{R} \$ 22,2$ bilhões. Ademais, os resultados apontam também para a necessidade de investimentos nos sistemas de esgotos (coleta e tratamento), a serem destinados a 2926 municípios, de forma a evitar o comprometimento da qualidade da água dos mananciais (ANA, 2011).
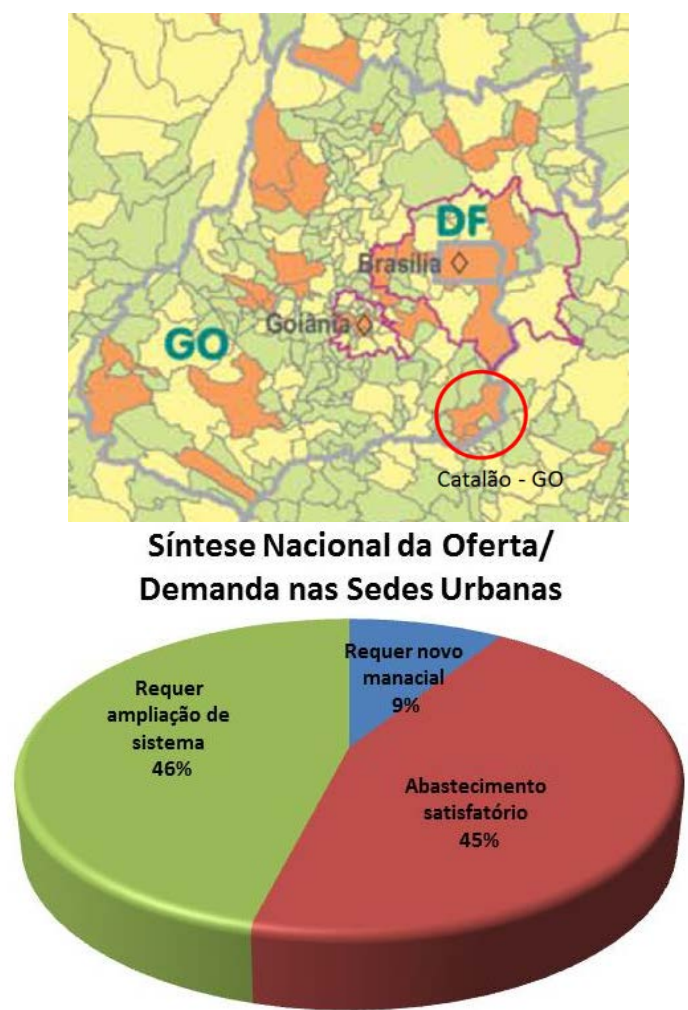

Figura 6: Destaque para a necessidade da adoção de outro manancial para o abastecimento. Fonte: adaptado de ANA (2011).

Segundo IBGE (2009) no censo sobre lavouras permanentes e temporárias 2004-2009 a cidade de Catalão cultiva cerca de $23 \%$ de sua área em 2004, aumentando para $26 \%$ em 2009, contudo houve uma variação nas áreas plantadas por cultura. Cabe salientar, que não se pode afirmar que todas às culturas abrangiam a bacia do Ribeirão Pari/Samambaia e que fossem cultivadas na mesma época, daí a oscilação no consumo de água para irrigação agrícola. A Tabela 5 mostra a lavoura e a área, respectiva, de plantio nos anos estudados.

Tabela 5. Levantamento das Lavouras cultivadas no Município de Catalão no ano de 2009. Fonte: IBGE (2009)

\begin{tabular}{|c|c|c|}
\hline Lavouras do Município de Catalão & 2004 & 2009 \\
\hline \multicolumn{3}{|c|}{ Lavouras Permanentes (hectares) } \\
\hline Café (em grão) - Área plantada & 720 & 410 \\
\hline Laranja - Área plantada & 60 & 400 \\
\hline Banana - área plantada & 5 & - \\
\hline Limão - área plantada & 5 & - \\
\hline Manga - área plantada & 10 & - \\
\hline Palmito - área plantada & 20 & - \\
\hline \multicolumn{3}{|c|}{ Lavouras Temporárias (hectares) } \\
\hline Algodão herbáceo (em caroço) - Área plantada & 1250 & 100 \\
\hline Alho - Área plantada & 100 & 20 \\
\hline Arroz (em casca) - Área plantada & 2000 & 500 \\
\hline Cana-de-açúcar - Área plantada & 100 & 800 \\
\hline Feijão (em grão) - Área plantada & 1300 & 1.360 \\
\hline Mandioca - Área plantada & 300 & 300 \\
\hline Milho (em grão) - Área plantada & 11.300 & 14.000 \\
\hline Soja (em grão) - Área plantada & 70.000 & 77.000 \\
\hline Sorgo (em grão) - área plantada & 320 & 3.380 \\
\hline Tomate - Área plantada & 120 & 100 \\
\hline Trigo (em grão) - Área plantada & 1.500 & 1.400 \\
\hline TOTAL & 89.110 & 99.770 \\
\hline
\end{tabular}


Com base em uma análise integrada realizada por Mosca (2004) através da aplicação de questionários aos produtores verificaram-se a predominância de pequenas e médias propriedades, baseadas no trabalho familiar.

$\mathrm{Na}$ época em que estes dados foram levantados pela autora, observou-se que destas propriedades $76,88 \%$ possuem menos de 20 ha, $15,63 \%$ das propriedades têm de 21 a 50 ha, 6,87\% possuem de 51 a 100 ha e $0,62 \%$ possui mais de 100 ha. Nestas propriedades $57,86 \%$ afirmaram não usar sistemas de irrigação, 8,81\% usam ocasionalmente e $33,33 \%$ utilizam regularmente.

Na Figura 7 estão apresentados os usos e ocupações do solo da sub-bacia do Ribeirão Pari/Samambaia em 2004 e na Figura 8 estão apresentados os usos e ocupações do solo obtidos através de mesclas de imagens de satélite dos anos de 2005, 2006 e 2009.

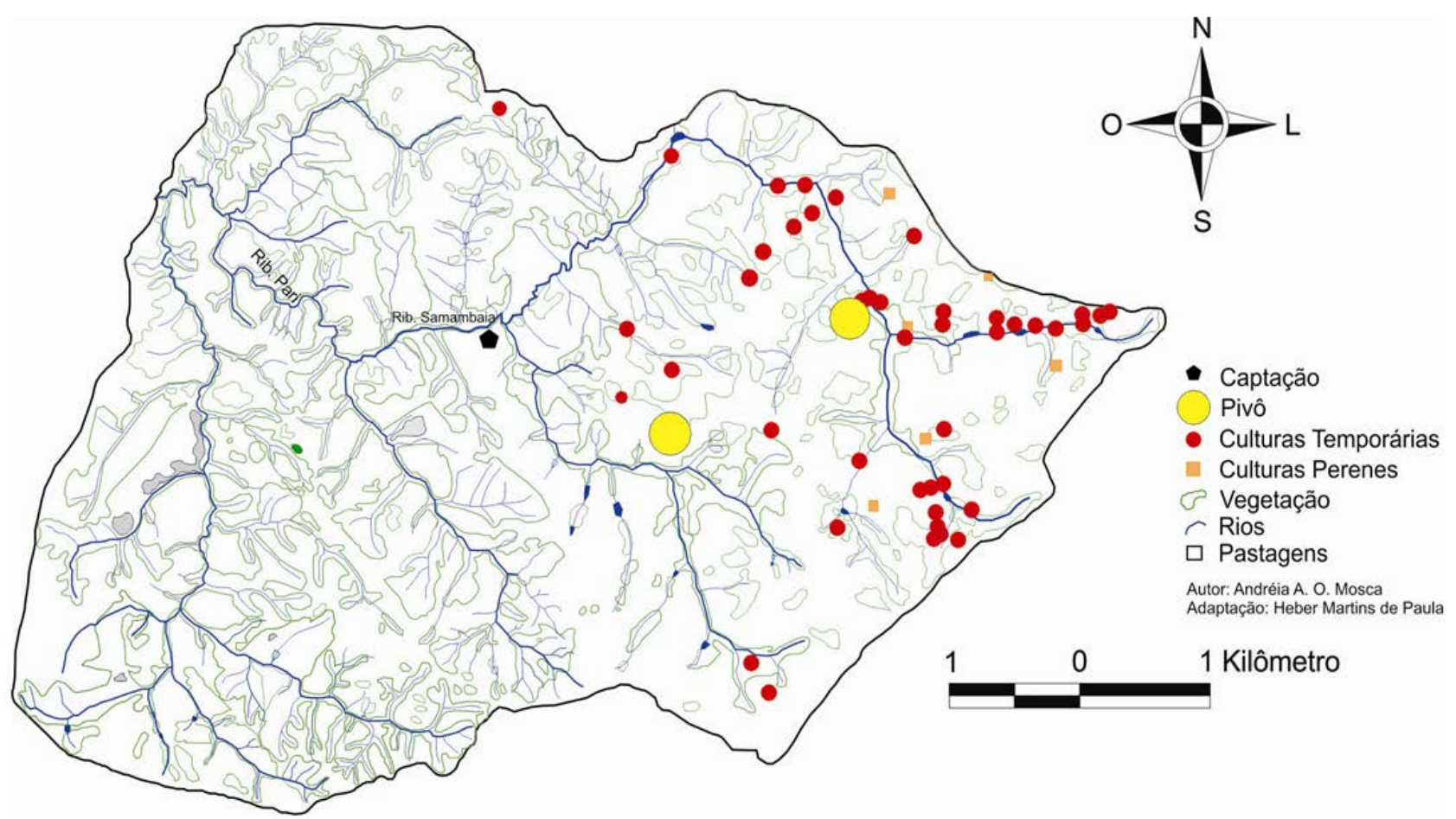

Figura 7: Mapa de Uso e Ocupação do Solo.

Fonte: Adaptado de Mosca (2004).
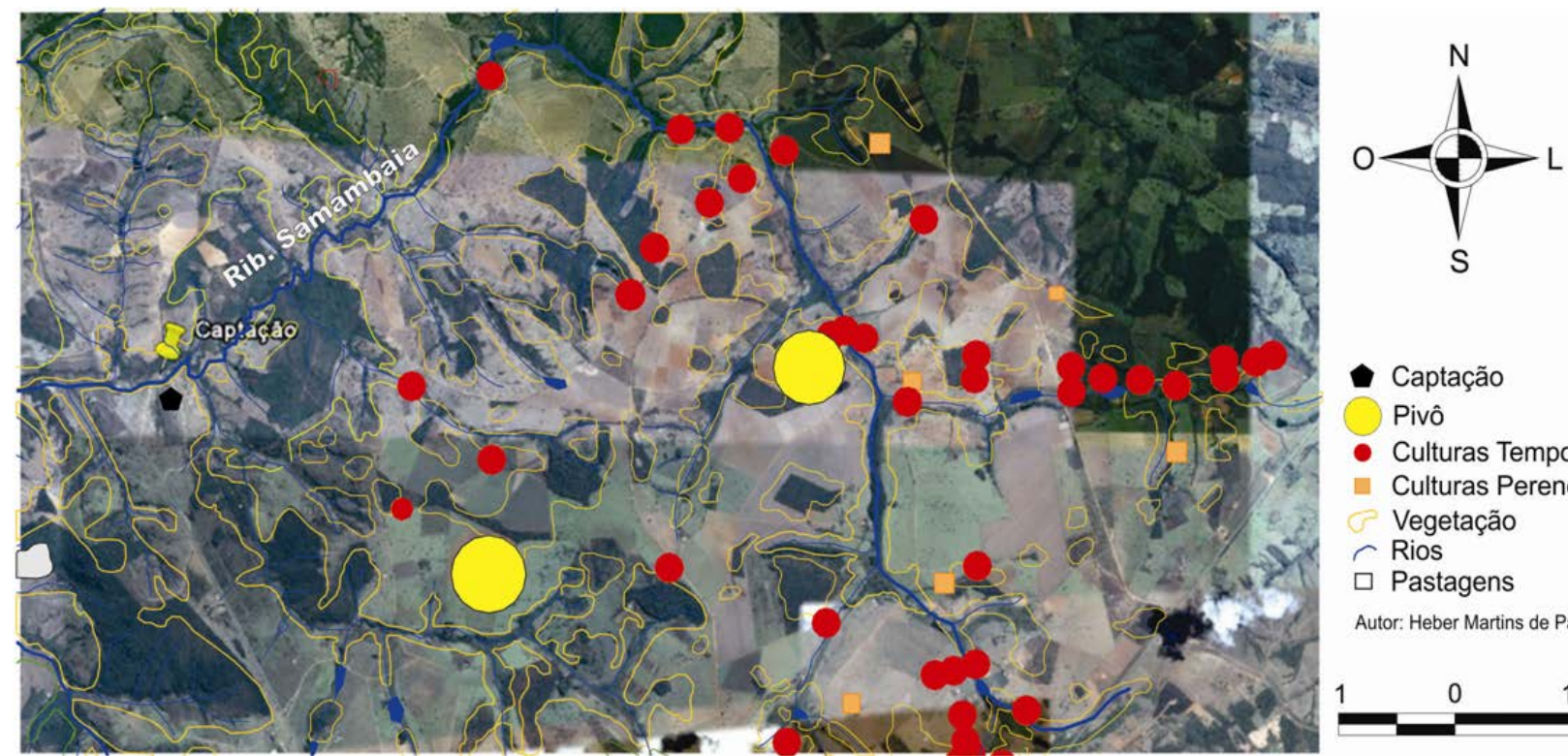

Captação

Pivô

- Culturas Temporárias

- Culturas Perenes

Vegetação

$\sim$ Rios

$\square$ Pastagens

Autor: Heber Martins de Paula

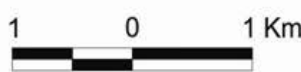

Figura 8: Mescla e Sobreposição de imagens de satélite de 2005, 2006 e 2009.

Fonte: Adaptado de Google Earth (2011). 
Nota-se que não houve uma alteração substancial do uso e ocupação do solo neste período, porém este estudo não pode ser afirmativo e sim dar uma idéia da situação atual, devendo-se dar continuidade ao trabalho de monitoramento de vazões do rio ao longo do tempo, bem como realizar investigações mais profundas acerca da utilização da água nesta sub-bacia.

\section{CONSIDERAÇÕES FINAIS}

Os monitoramentos das vazões realizadas em 1999 e 2000, já apontavam a necessidade de se estudar outro manancial para abastecimento visto às baixas vazões apresentadas. Já no monitoramento realizado nos meses de julho e agosto de 2011 apresenta uma vazão mínima de $0,46 \mathrm{~m}^{3} \mathrm{~s}^{-1}$, e, considerando $0,18 \mathrm{~m}^{3} \mathrm{~s}^{-1}$ de vazão necessária de água para a captação, esse quadro poderá comprometer, consideravelmente, o abastecimento de água para a cidade de Catalão para os próximos anos. Avaliando, ainda, o crescimento urbano da cidade, acima da média nacional, será de suma importância a implantação do gerenciamento e monitoramento da Bacia do Ribeirão Pari/Samambaia, para a consolidação de um banco de dados que servirá de apoio fundamental para atividades de um planejamento para bacia, que buscará o desenvolvimento social e econômico da região.

Portanto, recomenda-se aprofundar os estudos para uma caracterização mais detalhada dos conflitos entre demandas e ofertas hídricas da bacia, atividade que passa essencialmente, pela consolidação de bancos de dados que traduzam as realidades naturais, sociais e econômicas da bacia.

\section{REFERÊNCIAS BIBLIOGRÁFICAS}

ANA - Agência Nacional de Águas. Conjuntura dos Recursos Hídricos no Brasil: informe 2011. Brasília: ANA, 2011. 112p. Disponível em <http://conjuntura.ana.gov.br/conjuntura/download.aspx >. Acesso em 25 de julho de 2011.

CBH - Comitê das Bacias Hidrográficas. Mapa da Bacia Hidrográfica do Rio Paranaíba - Regiões Hidrográficas. Disponível em <http://www.paranaiba.cbh.gov.br>. Acesso em 26 de julho de 2011.

GOIÁS. SEMARH - Secretaria do Meio Ambiente e dos Recursos Hídricos. CERH - Conselho Estadual de Recursos Hídricos. Resolução $\mathrm{n}^{\circ}$ 9, de 2005. Estabelece o Regulamento do Sistema de outorga das águas de domínio do Estado de Goiás e dá outras providências. Goiânia, GO, 2005.

GOOGLE EARTH for Windows: Software de visualização de imagens de satélite. Versão 6.0.3.2197. Google Inc. 2011.
IBGE - Instituto Brasileiro de Geografia e Estatística. Produção agrícola municipal 2009 - Culturas temporárias e permanentes - v.36. Disponível em <http://www.ibge.gov.br/cidadesat/topwindow.htm?1>. Acesso em 25 de julho de 2011.

MOSCA, A.A.O. Diagnóstico sócio-ambiental da bacia do Ribeirão Pari/Samambaia: Catalão (GO). 2004, $153 \mathrm{f}$. Monografia (Bacharelado em Geografia). Universidade Federal de Goiás, Catalão, 2004.

ROLIM, G.S.; SENTELHAS, P.C.; BARBIERI, V. Planilhas no ambiente EXCEL para os cálculos de balanços hídricos: normal, sequencial, de cultura e de produtividade real e potencial. Revista Brasileira de Agrometeorologia, v.6, p.133-137, 1998.

SENTELHAS, P.C., PEREIRA, A.R., MARIN, F.R., ANGELOCCI, L.R., ALFONSI, R.R., CARAMORI, P.H., SWART, S. BHBRASIL - Balanços Hídricos Climatológicos de 500 Localidades Brasileiras. 2003. Disponível em <http://www.lce.esalq.usp.br/bhbrasil/>. Acesso em 27 de julho de 2011. 